\title{
Snare rotation technique: a simple tip for successful polypectomy for non-pedunculated gastrointestinal polyps
}

Snare resection for non-pedunculated polyps has a long history, and its application has been expanded to various methods such as endoscopic mucosal resection (EMR), cold polypectomy, and underwater EMR [1-3]. Various clinical tips and tricks have been demonstrated by experts [4,5]. In any snare resection for non-pedunculated polyps, a universally important issue is positioning the loop of the snare horizontal to the lesion. This positioning can avoid askew grasping of the polyp, thereby avoiding incomplete resection. However, the snare does not always emerge at the desired angle from the working channel of the scope. Here we demonstrate the "rotation technique" to reposition the loop of the snare to an ideal angle for grabbing the polyp horizontally ( $\vee$ Video 1 ).

When the snare emerges at an incorrect angle, it can be fixed while the assistant rotates the handle of the device to position the loop of the snare horizontal to the lesion ( $>$ Fig. 1, > Fig. 2). The part of the sheath outside the cap of the working channel of the scope should be straightened to facilitate rotation. During rotation, the electrical cord should be unplugged from the snare sheath to ease rotation of the handle and can be reconnected when the snare is at the expected angle. During rotation, it is recommended that the physician shake the sheath slightly to ease rotation of the snare. This is a very simple skill but extremely useful for better snare resection of non-pedunculated gastrointestinal polyps.

Endoscopy_UCTN_Code_TTT_1AQ_2AD

Competing interests

The authors declare that they have no conflict of interest.

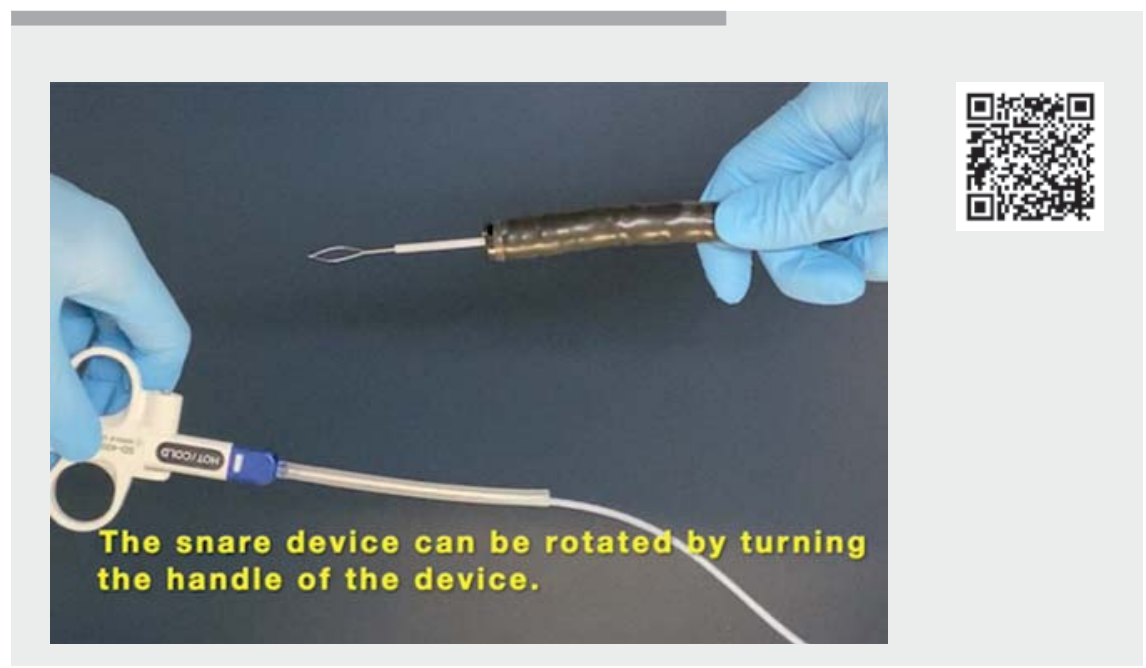

Video 1 Three cases including two colonic polyps and an esophageal lesion using "snare rotation technique" for polypectomy are presented.

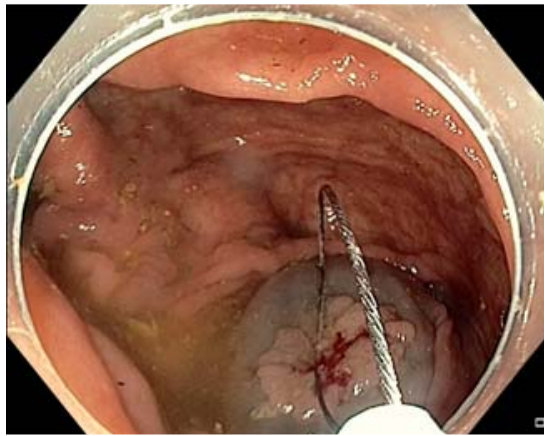

- Fig. 1 The angle of the snare is not horizontal to the lesion.

The authors

Shunsuke Yamamoto ${ }^{1}$, Adolfo Parra-Blanco $^{2}$

1 Department of Gastroenterology and Hepatology, National Hospital Organization Osaka National Hospital, Osaka, Japan

2 NIHR Nottingham Biomedical Research Centre, Department of Gastroenterology, Nottingham University Hospitals NHS Trust and University of Nottingham, Nottingham, UK

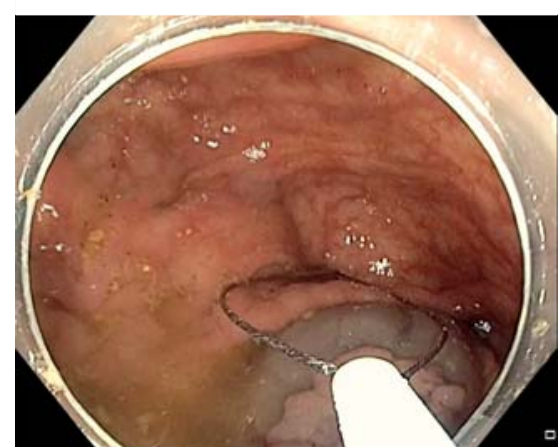

Fig. 2 The angle of the snare is fixed at an ideal position to the lesion.

Corresponding author

\section{Shunsuke Yamamoto, MD}

Department of Gastroenterology and Hepatology, NHO Osaka National Hospital, 2-1-14 Houenzaka, Chuo-ku, Osaka, 540-0006, Japan

shun0515suke@gmail.com 


\section{References}

[1] Ferlitsch M, Moss A, Hassan C et al. Colorectal polypectomy and endoscopic mucosal resection (EMR): European Society of Gastrointestinal Endoscopy (ESGE) Clinical Guideline. Endoscopy 2017; 49: 270-297

[2] Papastergiou V, Paraskeva KD, Fragaki M et al. Cold versus hot endoscopic mucosal resection for nonpedunculated colorectal polyps sized $6-10 \mathrm{~mm}$ : a randomized trial. Endoscopy 2018; 50: 403-411

[3] Binmoeller KF, Weilert F, Shah J et al. 'Underwater' EMR without submucosal injection for large sessile colorectal polyps (with video). Gastrointest Endosc 2012; 75: 1086 1091
[4] Bourke MF, Bhandari P. How I remove polyps larger than $20 \mathrm{~mm}$. Endoscopy 2019; 51 : 1151-1154

[5] Kaltenbach T, Anderson JC, Burke CA et al. Endoscopic removal of colorectal lesions: recommendations by the US Multi-Society Task Force on Colorectal Cancer. Gastrointest Endosc 2020; 91: 486-519

Bibliography

Endoscopy 2022; 54: E94-E95

DOI 10.1055/a-1394-6014

ISSN 0013-726X

published online 15.3.2021

(c) 2021. Thieme. All rights reserved.

Georg Thieme Verlag KG, Rüdigerstraße 14,

70469 Stuttgart, Germany
ENDOSCOPY E-VIDEOS

https:/|eref.thieme.de/e-videos

回屌 Endoscopy E-Videos is an

open access online section, 回: reporting on interesting cases and new techniques in gastroenterological endoscopy. All papers include a high quality video and all contributions are freely accessible online. Processing charges apply (currently EUR 375), discounts and wavers acc. to HINARI are available.

This section has its own submission website at

https://mc.manuscriptcentral.com/e-videos 